\title{
Repeated Surgical Procedure
}

National Cancer Institute

\section{Source}

National Cancer Institute. Repeated Surgical Procedure. NCI Thesaurus. Code C50830.

Repeat performance of a surgical procedure or intervention. (ACC) 